\title{
Awareness of the Pandemic H1N1 Influenza global outbreak 2009 among medical students in Karachi, Pakistan
}

\author{
Zubair Ali Khowaja ${ }^{1}$, Muhammad Idrees Soomro ${ }^{1}$, Abdul Khaliq Pirzada ${ }^{1}$, Muhammed Ahmed \\ Yoosuf $^{1}$, Vinod Kumar ${ }^{1,2}$ \\ ${ }^{1}$ Dow Medical College, Dow University of Health Sciences, Karachi, Pakistan \\ ${ }^{2}$ Community Medicine Department, Dow University of Health Science, Karachi, Pakistan
}

\begin{abstract}
Introduction: This study aimed to assess student awareness of the pandemic pdmH1N1, including the students' attitudes and perceptions about treatment, severity of disease and preventive measures.

Methodology: A cross-sectional study was conducted among medical students of Dow University of Health Sciences, Karachi. The data were collected through a self-administered questionnaire and results were analyzed using SPSS version 16.

Results: A total of 396 medical students participated in this study with a mean age of 21 ( \pm 1.4$)$. About 365 (92.2\%) were unaware of pdmH1N1. It was identified as a viral disease by $339(85.6 \%)$ students, and $282(71.2 \%)$ students correctly identified it as a disease affecting humans and pigs. The most common source of knowledge was television by $259(65.4 \%)$ respondents. Most common symptoms identified were fever by $287(72.5 \%)$, sore throat by 169 (42.7\%) and cough by $127(32.1 \%)$. Regarding vaccine, 290 (73.2\%) respondents replied that it is not available and $204(51.5 \%)$ said there is no treatment available for pdmH1N1. In severity scale $162(40.9 \%)$ students rated it as fatal disease. According to $205(51.8 \%)$ respondents, avoiding close contact with sick people is an effective preventive measure followed by washing hands with soap $150(37.1 \%)$.

Conclusion: The awareness regarding pdmH1N1 was not adequate among students regarding disease transmission, preventive measures, vaccinations, and available treatment. As the pdmH1N1 has become a worldwide public health problem and Pakistan is at risk of outbreak, increased awareness would be a solution to avoid its spread and complications.
\end{abstract}

Key words: pdmH1N1; Swine flu; flu awareness; influenza pandemic; student awareness

J Infect Dev Ctries 2011; 5(3):151-155.

(Received 30 May 2010 - Accepted 31 October 2010)

Copyright (C) 2011 Khowaja et al. This is an open-access article distributed under the Creative Commons Attribution License, which permits unrestricted use, distribution, and reproduction in any medium, provided the original work is properly cited.

\section{Introduction}

Flu is one of the oldest medical concerns, causing high mortality rates among humans. "Pandemic Influenza A/H1N1 2009" (pdmH1N1), which is commonly known as "Swine Influenza", emerged from North American pigs caused by H1N1 Influenza Virus, and spread globally in a short span of time resulting in high morbidity and mortality [1].

Historically, pdmH1N1 was first proposed to be a disease related to human influenza during the 1918 Flu Pandemic, when pigs and humans became sick simultaneously [2]. The 1918 Flu Pandemic was responsible for an estimated 50- to 100 million mortalities worldwide [3]. Recent strains of pdmH1N1 virus are considered to be descendants of what caused the 1918 flu pandemic [4]. In June 2009, the World Health Organization (WHO) declared the level of pdmH1N1 as pandemic on the basis of 177,475 confirmed laboratory cases and 1,462 deaths due to pdmH1N1 on 6 August 2009 [5]. Pakistan was warned of the outbreak of H1N1 pandemic 2009 on the confirmation of a case of H1N1virus in the country at Islamabad on 11 August2009.

Medical students have more contact with diseased people, leading to increased susceptibility for contracting an infectious disease. For that reason it is deemed necessary for a student to be well-aware of the outbreak of infectious disease, its transmission routes, methods of prevention and its vaccination.

The current study reports the awareness of Pandemic pdmH1N1 and attitudes toward the outbreak among the students of Dow University of Health Science, Karachi, Pakistan. The students' perceptions about vaccinations as well as their awareness of the treatment and severity of the disease are also reported. 
Table 1. Demographic characteristics of Participants

\begin{tabular}{|l|c|c|c|}
\hline \multicolumn{1}{|c|}{ Year } & $\begin{array}{c}\text { Students } \\
\text { surveyed }\end{array}$ & $\begin{array}{c}\text { Students } \\
\text { responded }\end{array}$ & $\begin{array}{c}\text { Respondent } \\
\text { percentage (\%) }\end{array}$ \\
\hline First year & 90 & 77 & 86 \\
\hline Second Year & 90 & 89 & 99 \\
\hline Third Year & 90 & 78 & 87 \\
\hline Fourth year & 90 & 77 & 86 \\
\hline Final year & 90 & 75 & 83 \\
\hline Total & 450 & 396 & 88 \\
\hline
\end{tabular}

Table 2. Known and unknown about Influenza A/H1N1

\begin{tabular}{|l|c|c|c|c|c|}
\hline \multicolumn{1}{|c|}{ Year } & $\begin{array}{c}\text { Student } \\
\text { respondents }\end{array}$ & Known & $(\%)$ & Unknown & $(\%)$ \\
\hline First year & 77 & 65 & 84.5 & 12 & 15.5 \\
\hline Second Year & 89 & 80 & 89.8 & 9 & 10.2 \\
\hline Third Year & 78 & 73 & 93.6 & 5 & 6.4 \\
\hline Fourth year & 77 & 73 & 94.8 & 4 & 5.2 \\
\hline $\begin{array}{l}\text { Final year } \\
\text { Total }\end{array}$ & 75 & 74 & 98.7 & 1 & 1.3 \\
\cline { 2 - 6 } & 396 & 365 & 92.1 & 31 & 7.8 \\
\hline
\end{tabular}

\section{Methodology}

This was a cross-sectional study conducted among medical students at Dow University of Health Science, Karachi, during October to November 2009. At the time of study, 1,502 students were registered at Dow University Health Science from first year to fifth year as medical students. We required a sample size of 309 subjects to fulfill the objectives of study at $95 \%$ confidence interval level and assuming 5\% bound error. All medical students of Dow University of Health Science were eligible to participate. The convenient sampling method was used, with equal distribution of questionnaires to students in each of the five years. Multiple choice questions were structured to contain two parts. The first part of the questionnaire covered demographic information regarding age, gender and class of enrollment in medical college. The second part covered questions regarding awareness of pdmH1N1. The questions were as follows: (i) Heard about Swine Flu (Influenza $\mathrm{A} / \mathrm{H} 1 \mathrm{~N}$ ); (ii) Source of information; (iii) What is pdmH1N1?; (iv) Cause of pdmH1N1; (v) Current status of pdmH1N1 in the world; (vi) Country commonly affected by pdmH1N1; (vii) Cases reported in Pakistan; (viii) Signs and symptoms of pdmH1N1; (ix) Is it a contagious disease?; (x) How does pdmH1N1 spread?; (xi) How long can an infected person spread pdmH1N1 to others?; (xii) Available treatments for pdmH1N1; (xiii) Vaccine available; (xiv) Preventive measures; (xv) Severity Scale; (xvi) Worried about current outbreak of pdmH1N1. Verbal Consent was taken and each participant was requested to fill out the questionnaire honestly. The nature of the study and the right to withdraw was fully explained to the participants. Strict confidentiality was ensured. The research was reviewed by the ethical committee of Dow University of Health Science, Karachi. Data was entered and analyzed in Statistical Package for Social Sciences version 16.0 (SPSS, Inc., Chicago, IL, USA).

Table 3. Source of information

\begin{tabular}{|l|c|c|}
\hline Source & Frequency of respondents & $(\boldsymbol{\%})$ \\
\hline Newspaper & 116 & 29.3 \\
\hline T.V. & 259 & 65.4 \\
\hline Internet & 74 & 18.7 \\
\hline Other & 43 & 10.9 \\
\hline
\end{tabular}


Table 4. Causes of Influenza A / H1N1

\begin{tabular}{|l|c|c|}
\hline Causes & Frequency of Respondents & $(\boldsymbol{\%})$ \\
\hline Bacteria & 7 & 1.8 \\
\hline Virus & 339 & 85.6 \\
\hline Parasite & 1 & 0.3 \\
\hline Fungi & 1 & 0.3 \\
\hline Unknown & 48 & 12.1 \\
\hline Total & 396 & 100 \\
\hline
\end{tabular}

\section{Results}

A total of 450 questionnaires were distributed equally among students in each year of medical college. Out of them $408(90.6 \%)$ questionnaires were returned but only $396(88 \%)$ questionnaires contained the complete information necessary for analysis. The mean age of the medical students who participated in the study was $21( \pm 1.4)$. There were $132(33.3 \%)$ males and $264(66.7 \%)$ females. The demographic data is summarized in Table 1.

Out of 396 participants, $365(92.2 \%)$ said that they had heard about pdmH1N1 (Table 2) and the most common source of information was television by 259 (65.4\%), followed by newspapers (116; $29.3 \%$ ) as shown in Table 3.

A total of $339(85.6 \%)$ students correctly answered that pdmH1N1 is caused by virus (Table 4), and $282(71.2 \%)$ said that it is a disease of pigs and humans. Most common symptoms identified were fever by $287(72.5 \%)$, sore throat by $169(42.7 \%)$ and cough by 127 (32.1\%) students (Table 5).

Table 5. Signs and Symptoms of Influenza A/H1N1

\begin{tabular}{|l|c|c|}
\hline $\begin{array}{c}\text { Signs and } \\
\text { symptoms }\end{array}$ & $\begin{array}{c}\text { Frequency of } \\
\text { respondents }\end{array}$ & $\mathbf{( \% )}$ \\
\hline Fever & 287 & 72.5 \\
\hline Cough & 127 & 32.1 \\
\hline Sore throat & 169 & 42.7 \\
\hline $\begin{array}{l}\text { Breathing } \\
\text { Difficulty }\end{array}$ & 98 & 24.7 \\
\hline Nausealvomiting & 53 & 13.4 \\
\hline $\begin{array}{l}\text { Decreased } \\
\text { Appetite }\end{array}$ & 38 & 9.6 \\
\hline
\end{tabular}

The current status of pdmH1N1 as a world pandemic was identified only by $155(39.1 \%)$ but 254 $(64.1 \%)$ said it commonly occurs in the United States, and 197 (49.7\%) students said that less than 10 cases were confirmed for pdmH1N1 in Pakistan up to November 2009. Regarding transmission, 346 $(87.4 \%)$ respondents said that pdmH1N1 is contagious and the most common mode of transmission identified by $252(63.6 \%)$ was infected air; $192(48.5 \%)$ students said that infected persons can spread the disease as long as they are symptomatic.

According to 205 (51.8\%) respondents, avoiding close contact with sick people is an effective preventive measure followed by washing hands with soap $(147 ; 37.1 \%)$, as shown in Figure 1. Travel restrictions were deemed necessary by $211(53.3 \%)$ students. Regarding vaccine, nearly two thirds of the students $(290 ; 73.2 \%)$ replied that it is not available and nearly half $(204 ; 51.5 \%)$ said there is no treatment available for pdmH1N1.

A total of $186(47 \%)$ students were in favor of arranging awareness programs for recent outbreaks of disease. Regarding severity, Table 6 shows that 162 students $(40.9 \%)$ rated pdmH1N1 a fatal disease and, $248(62.6 \%)$ were worried about the recent outbreak of disease.

Table 6. Severity Rating for Influenza A/H1N1

\begin{tabular}{|l|c|c|}
\hline Severity & $\begin{array}{l}\text { Frequency of } \\
\text { respondents }\end{array}$ & $(\boldsymbol{\%})$ \\
\hline Mildly dangerous & 20 & 5.1 \\
\hline $\begin{array}{l}\text { Moderate } \\
\text { dangerous }\end{array}$ & 62 & 15.7 \\
\hline Severely dangerous & 118 & 29.8 \\
\hline Fatal & 162 & 40.9 \\
\hline Unknown & 34 & 8.6 \\
\hline
\end{tabular}

\section{Discussion}

The pandemic H1N1 Influenza (pdmH1N1) was covered by the media after being declared as pandemic phase level 6 by the World Health Organization due to increased reported cases of Influenza A (H1N1) worldwide. In this study, most of the participants knew about pdmH1N1 and the most common source of information was television and newspapers. This result suggests that media health communicators play a significant role in 
Figure 1. Preventive measures for influenza A/H1N1

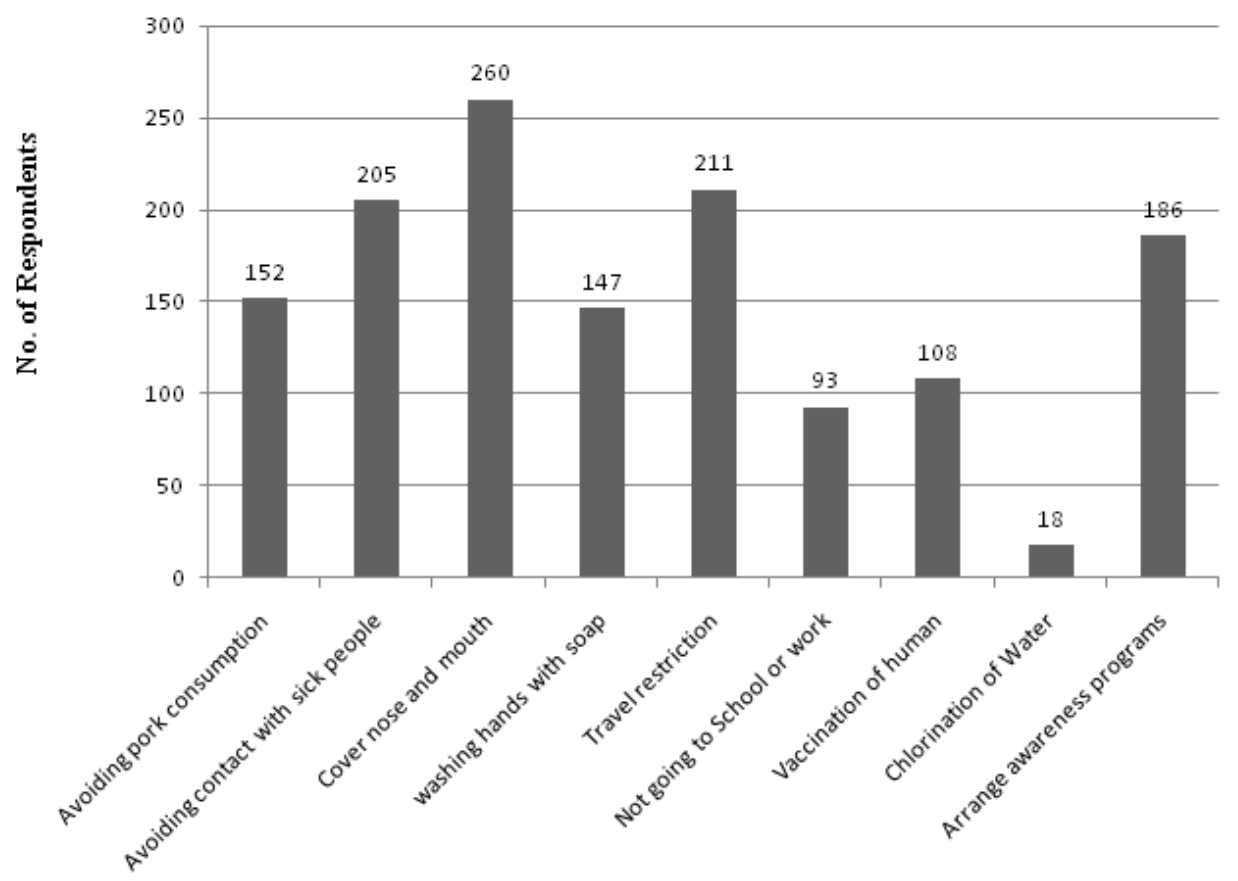

Types of Preventive measures

alarming the population about upcoming health problems and it is consistent with the study conducted by James Rubin et al. [6]. Television as major source of knowledge regarding pandemic 2009 was also identified by Shivlingesh Krishnappa Kamate et al. [7].

The situation in Pakistan regarding the total number of confirmed pdmH1N1 cases was correctly identified by the majority of respondents, but more than half of the participants did not correctly identify the worldwide status of pdmH1N1 as a pandemic. In this study, 39.1 participants correctly identified it as a pandemic, which is consistent with the findings of a similar study by Robert J. Blendon et al. [8].

According to the Centers for Disease Control (CDC), pdmH1N1 is a contagious disease that occurs in pigs and humans caused by an influenza virus strain. Zoonosis of pdmH1N1 viruses can occur directly from pigs to humans and also from humans to pigs. Specifically, transmission of pdmH1N1 from infected pigs to humans is likely to occur when people are in close proximity to the infected pigs, such as in pig barns and livestock exhibits housing pigs at fairs, but no transition has been detected by eating pork. In our study, the majority of the participants identified the disease correctly as a viral disease which is contagious and occurs in pigs and humans. The pig is not a native animal in Pakistan, so the most common source of transmission is from human to human through infected air. This important fact for taking precautions was not perceived by one third of the participants.

According to the CDC, symptoms of pdmH1N1 in humans are similar to the symptoms of regular human seasonal influenza and include fever, lethargy, lack of appetite, and coughing. Some people with pdmH1N1 also have reported runny nose, sore throat, nausea, vomiting and diarrhoea. In this study, most of the participants identified fever and lethargy as the most common complaint along with sore throat, cough, and difficulty breathing.

Nearly half of the participants believed that infected persons can spread pdmH1N1 as long as they are symptomatic. According to the CDC, people infected with seasonal and pdmH1N1 influenza shed virus and may be able to infect when they are asymptomatic from day 1 before getting sick to five to seven days afterward.

In this study, $51.3 \%$ of the participants reported that there is no treatment available and 37.9\% participants said that infected persons with pdmH1N1 cannot be treated. But, according to the World Health Organization, oseltamivir is used for both treatment and prophylaxis of pdmH1N1 and treatment should be continued for five days. 
Regarding severity, $40 \%$ of the participants rated pdmH1N1 as a fatal disease and $30 \%$ as severely dangerous. According to CDC estimates, illness with 2009 H1N1 virus has ranged from severe to mild and self-limiting disease. The respondents' perception of high fatality due to pdmH1N1 may be due to their knowledge of previous influenza pandemic mortalities and the highly reported cases of hospitalizations and deaths among people younger than 65 years of age relative to people 65 and older compared with seasonal influenza during the 2009 H1N1 pandemic.

Regarding preventive measures of pdmH1N1, respondents in this study rated covering the nose and mouth followed by avoiding contact with others as the most effective methods for prevention of Influenza A (H1N1). Shivlingesh Krishnappa Kamate et al. [7] and Lau et al. [9] also reported that the respondents in their studies considered covering the nose and mouth with face masks the most effective preventive measure. Respondents in a study by Seale et al. rated quarantine as the most effective measure for preventing Influenza A (H1N1) [10].

\section{Limitations}

Study to assess the awareness regarding the disease Pandemic pdmH1N1 among the society, in that respect work had started from the students of a medical college and noted that the students are more aware about the outbreak of disease pdmH1N1 in comparison to the general public. During the study the specific part of population was surveyed in a specific time. It is unfair to collect data or measures the awareness regarding disease only in specific time and a group of the society instead of different parts of the society in the different periods. Our survey measured a specific population view at a specific point in time and their awareness reflects the information available at the time, so this survey may not accurately reflect respondents' real world responses.

\section{Conclusion}

At the time of this study there were no high levels of morbidity and mortality due to pdmH1N1 in Pakistan, but it was under threat of outbreak as large number of pdmH1N1 cases were reported in neighbouring countries. This study shows that a large number of students did not have complete awareness about disease transmission, preventive measures, vaccinations, and treatments available. Therefore, awareness programs should be developed to spread knowledge in the community in general and especially to those who are more susceptible to become infected.

\section{References}

1. Kahn CM (2005) The Merck Veterinary Manual, 9th Edition. New Jersey: Merck and Co. Inn Press, 1027-1032 p.

2. Knobler S, Mack A, Mahmoud A, Lemon SM (2005), The Threat of Pandemic Influenza: Are We Ready? Washington: National Academies Press, 62 p.

3. Patterson KD and Pyle GF (1991) The geography and mortality of the 1918 influenza pandemic. Bull Hist Med 65: 4-21.

4. Taubenberger JK and Morens DM (2006) 1918 Influenza: the mother of all pandemics. Emerg Infect Dis 12: 15-22. PMID $16494711 . \quad$ Available: http://www.cdc.gov/ncidod/eid/vol12no01/05-0979.htm.

5. Chan M (2009). World now at the start of 2009 influenza pandemic. World Health Organization (WHO) Available: http://www.who.int/mediacentre/news/statements/2009/h1n1 _pandemic_phase6_20090611/en/index.html. Accessed 25 October2009.

6. Rubin GJ, Amlot R, Page L, Wessely S (2009) Public perceptions, anxiety, and behavior change in relation to the swine flu outbreak: cross-sectional telephone survey. BMJ 339: 2651.

7. Kamate SK, Agrawal A, Chaudhary H, Singh K, Mishra P, Asawa K (2009) Public knowledge, attitude and behavioural changes in an Indian population during the Influenza A (H1N1) outbreak. J Infect Dev Ctries 4: 7-14.

8. Blendon RJ, Koonin LM, Benson JM, Cetron MS, Pollard WE, Mitchell EW, Weldon KJ, Herrmann MJ (2008) Public response to community mitigation measures for pandemic influenza. Emerg Infect Dis 14: 778-786.

9. Lau JTF, Yang X, Tsui H, Kim JH (2003) Monitoring Community responses to SARS epidemic in Hong Kong: from day 10 to day 62. J Epidemiol Community Health 57: 864-870.

10. Seale H, McLaws M-L, Heyood AE (2009) The Community's attitude towards swine flu and pandemic influenza. Medical Journal of Australia 191: 267-269.

\section{Corresponding author}

Zubair Ali Khowaja

Flat B-15 Prime Garden

Garden East Karachi

Pakistan - 74000

Phone: +92332-3402729

Email: zubair_khowaja@hotmail.com

Conflict of interests: No conflict of interests is declared. 